\title{
Effects of salinity on growth performance of early juveniles of Spotted scat (Scatophagus argus)
}

\author{
Le Quoc Viet ${ }^{1}$, Tran Ngoc Hai ${ }^{1}$ \\ College of Aquaculture and Fisheries, Can Tho University \\ DOI: 10.29322/IJSRP.11.07.2021.p11549 \\ http://dx.doi.org/10.29322/IJSRP.11.07.2021.p11549
}

\begin{abstract}
This study aimed to determine the appropriate salinity range for early juvenile of spotted scat fish (Scatophagus argus). The experiment included 7 treatments of salinity as $5,10,15,20$, 25,30 , and $35 \%$. The experiment was randomly set up in $100 \mathrm{~L}$ tanks in triplicate. The fish was stocked at 1 ind./L of stocking density with the initial weight, body length and body high were $0.022 \pm 0.002 \mathrm{~g}, 7.83 \pm 1.84 \mathrm{~mm}$, and $4.26 \pm 0.35 \mathrm{~mm}$, respectively. After 20 days of rearing, no significant difference in fish growth performance (DWG and SGRW; DDG and SGRD; DLG and SGRL) was observed among treatments ( $p>0.05)$. The fish survival ranged from 56.7 to $98.9 \%$, and was statistically different among treatments $(\mathrm{p}<0.05)$. In which, the highest survival rates were recorded at 5 and $10 \%$ of salinity (98.9 and $90.6 \%$, respectively) $(\mathrm{p}<0.05)$.
\end{abstract}

Index Terms- Spotted scat, Scatophagus argus, salinity, growth performance

\section{INTRODUCTION}

$S^{n}$ potted Scat (Scatophagus argus) is a euryhaline fish and widely distributed in brackish and marine waters of the IndoPacific and Southeast Asia (Mookkan et al., 2014; Su et al., 2019). Recently, Spotted Scat become a popular and important food fish due to its good taste and nutrient quality with high protein content (Sivan et al. 2007, 2010; Shi et al. 2015). Due to its herbivorous habitat and high tolerance to environmental stress, this fish has integrated cultured in shrimp ponds to prevent overgrowth of algae and seaweeds (Shao et al., 2004; Quốc Việt et al., 2020). However, the rapid rise in the demand for S. argus fish fry led to increased harvesting, which threatens the natural resources (Su et al., 2019).

In Vietnam, some studies have developed protocols for artificial breeding as well as the larval rearing for this species (Khanh et al., 2010a; Khanh et al., 2010b; Khanh et al., 2014). However, the environmental requirements for this species still need to be investigated. Spotted scat has been well known as a euryhaline fish with strong adaptability to salinity in nature (Gupta 2016), however, the appropriate salinity preferences for growth and survival have not yet been evaluated, especially in terms of early growth stages. Importantly, salinity affects the standard metabolic rate of fish (Ern and Esbaugh, 2018), fish ingestion rate, conversion efficiency, metabolism, and hormone secretion, thus affecting the growth of the body and the accumulation of nutrients (Bœuf and Payan, 2001; Ern et al., 2014; Xu et al., 2020). Therefore, this study proposed to evaluate effects of salinity on survival and growth performance of $S$. argus at early juvenile stage for optimization the production technology leading to the sustainable production of $S$. argus for mariculture.

\section{MATERIALS AND METHODS}

\subsection{Experimental design and management}

The experiment was randomly set up with six different salinity levels $(5,10,15,20,25,30$, and $35 \%$ o) in a series of 100 $\mathrm{L}$ tanks. Each treatment was conducted in triplicate and each replicate consisted of 60 juveniles at 23 days after hatching (DAH). The initial sizes of the juvenile were $0.022 \pm 0,002 \mathrm{~g}$ of body weight and $7.83 \pm 1.84 \mathrm{~mm}$ of total length. For the salinity acclimation, the fishes were initially stocked at $25 \%$ of salinity, then gradually reduced or increased salinity by $5 \%$ every 2 days until attain desired salinities (Khanh et al., 2010b).

Fishes were fed with Artemia nauplii enriched with DHA Selco (INVE Aquaculture Nutrition) and commercial pellet (INVE Thailand, containing 55\% of protein and 9\% of lipid). For Artemia, after 36h of incubation, the nauplii were harvested and enriched with DHA Selco at $0.4-0.6 \mathrm{~g} / \mathrm{L}$ for $12 \mathrm{~h}$. The enriched Artemia was fed twice a day at 7 AM and 3 PM for the first 5 days of the experiment. The commercial feed was alternatively fed from $25 \mathrm{DAH}$ at $7 \mathrm{AM}, 10 \mathrm{AM}, 1 \mathrm{PM}, 4 \mathrm{PM}$, and $6 \mathrm{PM}$; and switched to commercial feed only from $28 \mathrm{DAH}$. Water exchange (30\%) and siphon were regularly done every 2 days. The experiment was lasted for 20 days.

\subsection{Sampling \\ Water quality parameters}

Dissolved oxygen (DO), temperature, and $\mathrm{pH}$ were monitored twice daily (at 7 AM and 2 AM) using a digital meter (HI-98196 Multi-Parameter Waterproof Meter, HANNA Instruments, Ltd.). Total ammonium nitrogen (TAN) and nitrite were weekly measured using Sera testkits (Germany).

\section{Fish}

Every 10 days, the sampling was randomly conducted, wherein 10 fishes per tank were individually measured body weight and total length. At the end of the experiment, 30 fishes from each tank were measured to determine daily weight gain (DWG), specific growth rate (SGR), daily length gain (DLG) and specific growth rate in length $\left(\mathrm{SGR}_{\mathrm{L}}\right)$, daily body depth gain (DDG) and specific growth rate in body depth ( $\left.\mathrm{SGR}_{\mathrm{D}}\right)$ as follows: 


$$
\begin{gathered}
\text { DWG }=\frac{\text { Final weight }- \text { Initial weight }}{\text { Day of culture }} \\
\text { SRG }(\%)=\frac{100 *(\text { Ln final weight }- \text { Ln initial weight })}{\text { Day of culture }} \\
\text { DWG }=\frac{\text { Final weight }- \text { Initial weight }}{\text { Day of culture }} \\
\text { DLG }=\frac{\text { Final length }- \text { Initial length }}{\text { Day of culture }} \\
\text { SGRL }(\%)=\frac{100 *(\text { Ln Final length }- \text { Ln Initial length })}{\text { Day of culture }} \\
\text { DDG }=\frac{\text { Final depth }- \text { Initial depth }}{\text { Day of culture }} \\
\text { SGRL }(\%)=\frac{100 *(\text { Ln Final depth }- \text { Ln Initial depth })}{\text { Day of culture }}
\end{gathered}
$$

The survival rate (SR) of fish was estimated after 20 days of rearing:

$$
\text { SR }(\%)=\frac{\text { Final stock } * 100}{\text { Inital stock }}
$$

Table 1. The mean of temperature and $\mathrm{pH}$ value during the experimental time

\begin{tabular}{lllllll}
\hline \multirow{2}{*}{$\begin{array}{l}\text { Salinity level } \\
(\%)\end{array}$} & \multicolumn{2}{c}{ Temperature $\left({ }^{\circ} \mathbf{C}\right)$} & pH & \multicolumn{3}{c}{ Oxy $(\mathbf{m g} / \mathbf{L})$} \\
\cline { 2 - 7 } $\mathbf{5}$ & $\mathbf{A M}$ & $\mathbf{A M}$ & $\mathbf{P M}$ & $\mathbf{A M}$ & $\mathbf{P M}$ \\
\hline $\mathbf{5}$ & $28.09 \pm 0.40$ & $29.64 \pm 1.29$ & $8.10 \pm 0.24$ & $8.18 \pm 0.16$ & $4.52 \pm 0.30$ & $4.69 \pm 0.15$ \\
$\mathbf{1 0}$ & $28.08 \pm 0.39$ & $29.97 \pm 0.57$ & $8.02 \pm 0.23$ & $8.16 \pm 0.17$ & $4.54 \pm 0.24$ & $4.80 \pm 0.10$ \\
$\mathbf{2 0}$ & $28.09 \pm 0.39$ & $29.99 \pm 0.56$ & $7.98 \pm 0.19$ & $8.14 \pm 0.12$ & $4.55 \pm 0.34$ & $5.50 \pm 1.56$ \\
$\mathbf{2 5}$ & $28.06 \pm 0.36$ & $29.83 \pm 0.57$ & $7.97 \pm 0.20$ & $8.10 \pm 0.17$ & $4.52 \pm 0.24$ & $4.65 \pm 0.13$ \\
$\mathbf{3 0}$ & $28.08 \pm 0.32$ & $29.92 \pm 0.53$ & $7.94 \pm 0.21$ & $8.13 \pm 0.13$ & $4.54 \pm 0.25$ & $4.69 \pm 0.15$ \\
$\mathbf{3 5}$ & $28.13 \pm 0.34$ & $30.26 \pm 0.42$ & $7.94 \pm 0.22$ & $8.09 \pm 0.16$ & $4.51 \pm 0.31$ & $4.76 \pm 0.11$ \\
\hline
\end{tabular}

\subsubsection{Total ammonium nitrogen (TAN) and nitrite}

TAN levels among treatments fluctuated from 0.56 to $1.31 \mathrm{ppm}$, in which, the lowest TAN level was recorded at $15 \%$ treatment and the highest level was in 25\%o treatment (Table. 2). The concentration of TAN was not significantly different among treatments and. TAN concentration in water less than $1.5 \mathrm{mg} / \mathrm{L}$ was considered a safe dose for fish, but TAN toxicity would be increasing when $\mathrm{pH}$ value was higher than 8.5 (Tucker, 1998). Furthermore, TAN level within $0.2-2 \mathrm{ppm}$ is appropriate for hatchery practices. Generally, TAN levels in all treatments were in a suitable range for the normal development of fish.

\subsection{Statistical Analysis}

Data were presented as mean \pm standard division (SD) and were subjected to one-way ANOVA (SPSS 16.0 for Windows, IBM, Armonk, NY, USA) and Duncan's test was applied. All differences were considered at $\alpha=0.05$.

\section{RESULTS AND DISCUSSION}

\subsection{Water quality parameters}

\subsubsection{Temperature, $\mathrm{pH}$ and dissolve oxygen (DO)}

During the experimental time, the temperature, $\mathrm{pH}$ and $\mathrm{DO}$ ranged from $28.06-30.26^{\circ} \mathrm{C}, 7.93-8.18$, and $4.49-4.8 \mathrm{mg} / \mathrm{L}$, respectively (Table 1). According to Boyd (1998), the optimal value of $\mathrm{pH}$ for aquatic animals should be in range from 6.5 - 9.0, especially, for scat was within 7-8.5. Similarly, William and Robert (1997) suggested that the appropriate $\mathrm{pH}$ value for fish and shrimp ranged from 6.5 to 9.0 , but the fluctuation within a day should not be more than 0.5 .
Variation of nitrite concentration was from 0.42 to $1.11 \mathrm{mg} / \mathrm{L}$, in which, the lowest concentration was observed in 30\% treatment and the highest concentration was in 15\%o (Table 2). At 20\%o of salinity, the nitrite level was high $(1.06 \mathrm{mg} / \mathrm{L})$, but did not significantly affect the fish growth due to the decrease of nitrite toxicity in high salinity conditions. According to Boyd (1990), nitrite toxicity was reduced in high salinity condition because of the effects of $\mathrm{Ca}^{2+}$ and $\mathrm{Cl}^{-}$. Schwedler et al (1985) also reported that chloride concentration, $\mathrm{pH}$, fish size, nutritional status, disease infections, DO... were considerably related to nitrite toxicity.

Table 2. The mean of TAN and nitrite levels among treatments during the experimental time

\begin{tabular}{lll}
\hline Salinity level (\%) & Nitrite (mg/L) & TAN (mg/L) \\
\hline $\mathbf{5}$ & $0.75 \pm 0.30$ & $0.89 \pm 0.35$ \\
$\mathbf{1 0}$ & $1.06 \pm 0.34$ & $0.89 \pm 0.24$ \\
$\mathbf{1 5}$ & $1.11 \pm 0.13$ & $0.56 \pm 0.10$
\end{tabular}




\begin{tabular}{lll}
$\mathbf{2 0}$ & $1.06 \pm 0.21$ & $0.75 \pm 0.08$ \\
$\mathbf{2 5}$ & $0.97 \pm 0.13$ & $1.31 \pm 0.35$ \\
$\mathbf{3 0}$ & $0.42 \pm 0.01$ & $1.03 \pm 0.32$ \\
$\mathbf{3 5}$ & $0.56 \pm 0.24$ & $0.97 \pm 0.35$ \\
\hline
\end{tabular}

\subsection{Growth performance of fish \\ 3.2.1 Growth in total length}

The growth in total length of fish was presented in Fig. 1 and Table 3. Fishes were recorded with the initial length at $7.83 \pm$ $1.84 \mathrm{~mm}$; after 10 days of rearing, the total length reached to 9.63 $-11.23 \mathrm{~mm}$, and $17.58-19.03 \mathrm{~mm}$ after 20 days. Subsequently, the daily weight gain (DWG) was at 0,49 - 0,56 $\mathrm{mm} /$ day, coinciding with $\mathrm{SGR}_{\mathrm{L}}=4,04-4,42 \%$ /day (Table 3 ), but no statistical difference was observed among treatments $(p>0,05)$.
Therefore, the salinity did not affect the growth in total length of spotted scat juvenile.

According to Khanh et al. (2010b), the spotted scat reared at $15 \%$ of salinity showed the fastest growth for the first month of rearing, however, the fishes reared at 5\% was observed with greater growth in length from month $1(0.36 \pm 0.02 \mathrm{~mm})$, month 2 $(0.49 \pm 0.03 \mathrm{~mm})$, and month $3(0.21 \pm 0.02 \mathrm{~mm})$ which were significantly higher than others. Especially, fish showed low growth at $0 \%$ o $(0.13 \pm 0.04 \mathrm{~mm})$ and $30 \%,(0.11 \pm 0.01 \mathrm{~mm})$.

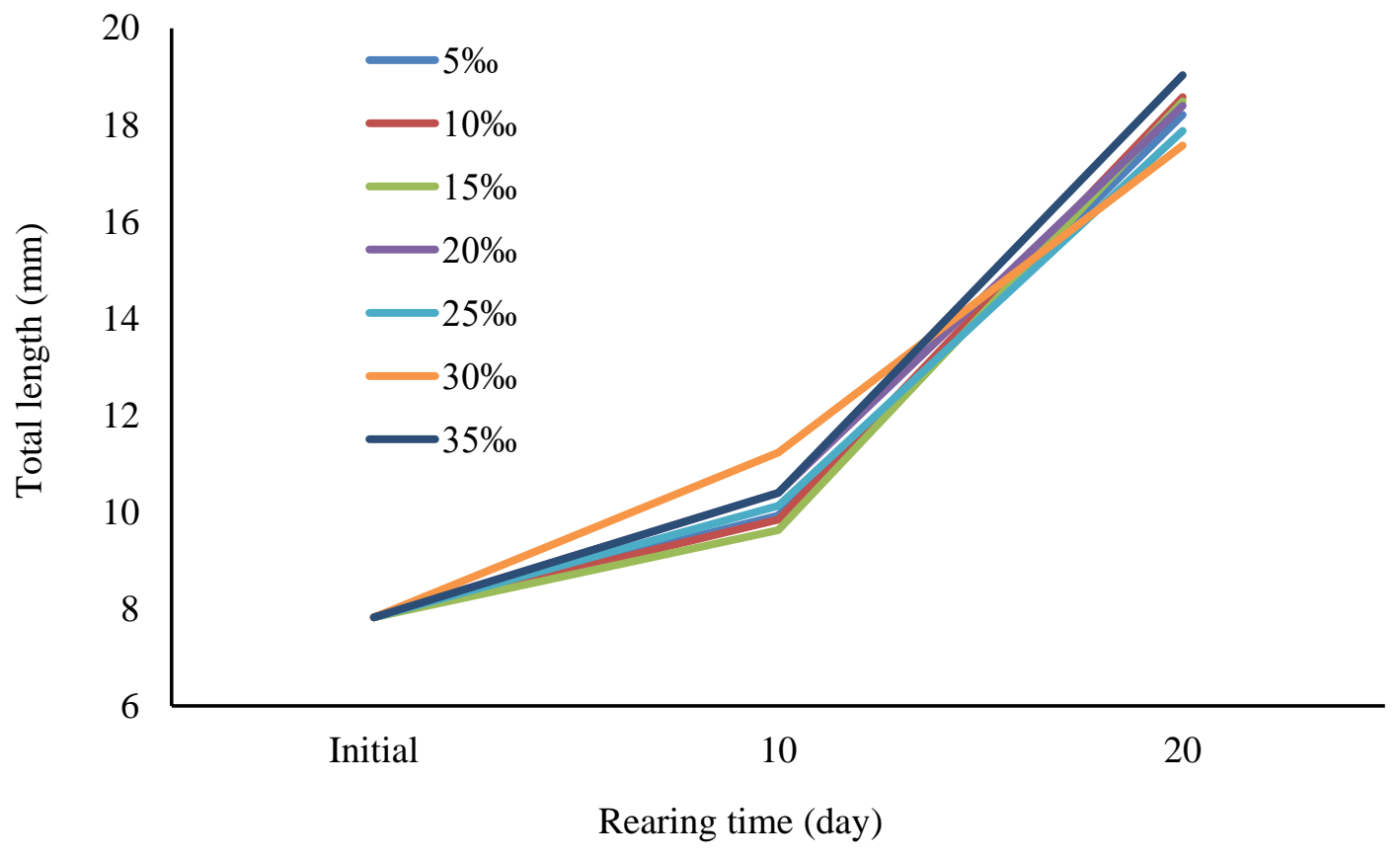

Figure 1: The total length of fishes during the experimental time

Table 3: Growth in fish length after 20 days of rearing

\begin{tabular}{lllll}
\hline $\begin{array}{l}\text { Salinity level } \\
(\%)\end{array}$ & $\mathbf{L}_{\mathbf{i}}(\mathbf{m m})$ & $\mathbf{L f}(\mathbf{m m})$ & $\begin{array}{l}\text { DLG } \\
(\mathbf{m m} / \mathbf{d a y})\end{array}$ & SGR $_{\mathbf{L}}(\boldsymbol{\%} / \mathbf{n g a ̀ y})$ \\
\hline $\mathbf{5}$ & $7.83 \pm 1.84$ & $18.21 \pm 0.21^{\mathrm{a}}$ & $0.52 \pm 0.01^{\mathrm{a}}$ & $4.22 \pm 0.06^{\mathrm{a}}$ \\
$\mathbf{1 0}$ & $7.83 \pm 1.84$ & $18.58 \pm 0.73^{\mathrm{a}}$ & $0.54 \pm 0.04^{\mathrm{a}}$ & $4.32 \pm 0.19^{\mathrm{a}}$ \\
$\mathbf{1 5}$ & $7.83 \pm 1.84$ & $18.49 \pm 0.71^{\mathrm{a}}$ & $0.53 \pm 0.04^{\mathrm{a}}$ & $4.29 \pm 0.19^{\mathrm{a}}$ \\
$\mathbf{2 0}$ & $7.83 \pm 1.84$ & $18.40 \pm 0.45^{\mathrm{a}}$ & $0.53 \pm 0.02^{\mathrm{a}}$ & $4.27 \pm 0.12^{\mathrm{a}}$ \\
$\mathbf{2 5}$ & $7.83 \pm 1.84$ & $17.88 \pm 0.12^{\mathrm{a}}$ & $0.50 \pm 0.01^{\mathrm{a}}$ & $4.12 \pm 0.01^{\mathrm{a}}$ \\
$\mathbf{3 0}$ & $7.83 \pm 1.84$ & $17.58 \pm 0.35^{\mathrm{a}}$ & $0.49 \pm 0.02^{\mathrm{a}}$ & $4.04 \pm 0.09^{\mathrm{a}}$ \\
$\mathbf{3 5}$ & $7.83 \pm 1.84$ & $19.03 \pm 1.94^{\mathrm{a}}$ & $0.56 \pm 0.09^{\mathrm{a}}$ & $4.42 \pm 0.50^{\mathrm{a}}$ \\
\hline
\end{tabular}

Means with similar superscripts in the same column are not significantly different ( $p>0.05)$ 


\subsubsection{Growth in body depth (BD)}

Growth in body depth was presented in Fig. 2 and Table 4. The initial BD size was at $4.26 \pm 0.35 \mathrm{~mm}$, and reached to $4.98-$ $6.07 \mathrm{~mm}$ after 10 days of rearing.
At day 20, the BD size ranged from $8.94-9.74 \mathrm{~mm}$, coinciding with $0.23-0.27 \mathrm{~mm} /$ day of DDG and 3,71-4,11\%/day of $\mathrm{SGR}_{\mathrm{D}}$. No significant difference in BD size was observed among treatments $(p>0.05)$. Therefore, the salinity level was not affect the BD of spotted scat.

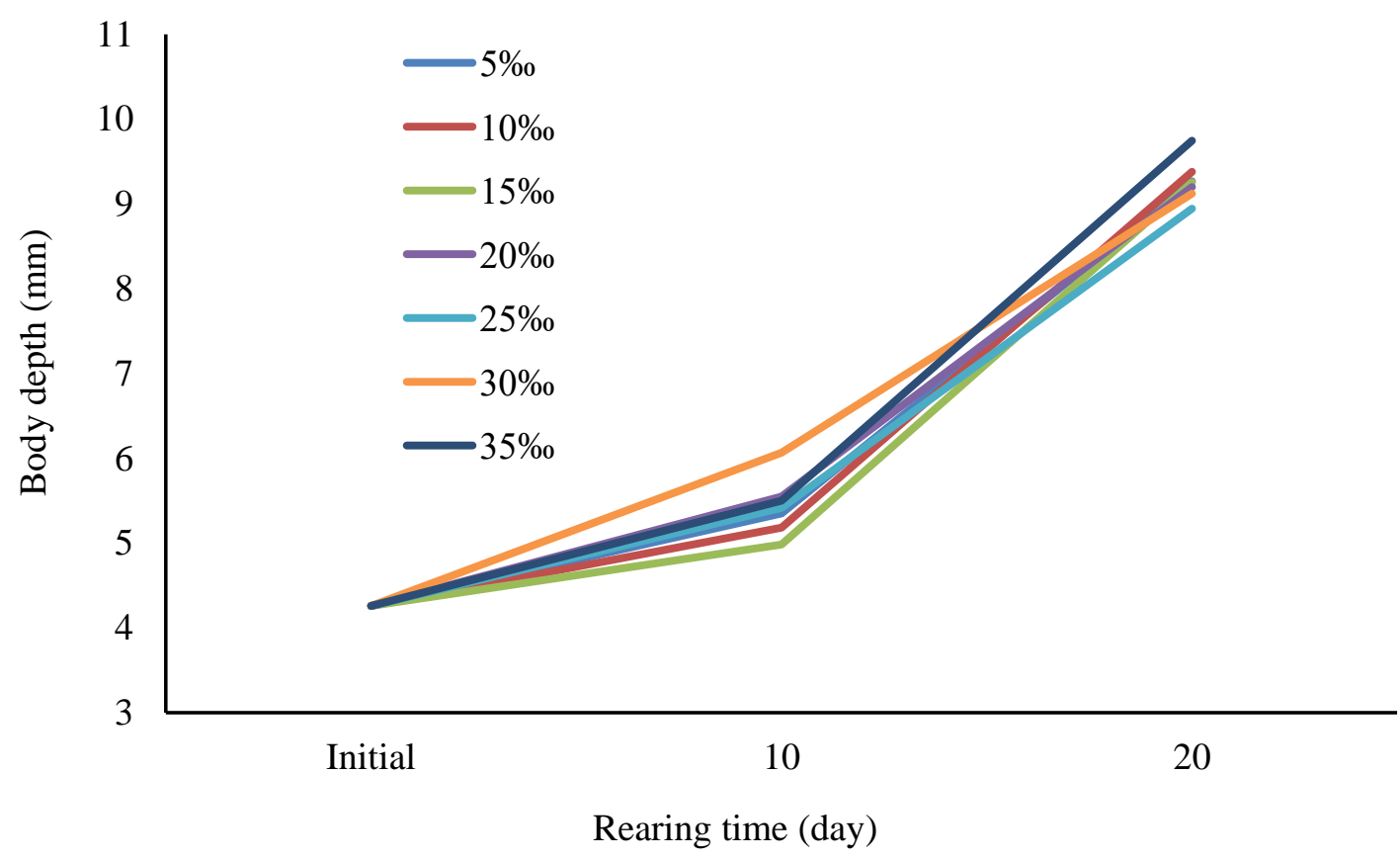

Figure 2: Body depth of spotted scat during the experimental time

Table 4: Growth in body depth of spotted scat after 20 days of rearing

\begin{tabular}{lllll}
\hline $\begin{array}{l}\text { Salinity level } \\
(\%)\end{array}$ & $\mathbf{H}_{\mathbf{i}}(\mathbf{m m})$ & $\mathbf{H}_{\mathbf{f}}(\mathbf{m m})$ & $\begin{array}{l}\text { DDG } \\
(\mathbf{m m} / \mathbf{d a y})\end{array}$ & SGRo $(\boldsymbol{\%} /$ day $)$ \\
\hline $\mathbf{5}$ & $4.26 \pm 0.35$ & $9.27 \pm 0.30^{\mathrm{a}}$ & $0.25 \pm 0.02^{\mathrm{a}}$ & $3.89 \pm 0.17^{\mathrm{a}}$ \\
$\mathbf{1 0}$ & $4.26 \pm 0.35$ & $9.38 \pm 0.39^{\mathrm{a}}$ & $0.26 \pm 0.02^{\mathrm{a}}$ & $3.94 \pm 0.21^{\mathrm{a}}$ \\
$\mathbf{1 5}$ & $4.26 \pm 0.35$ & $9.26 \pm 0.62^{\mathrm{a}}$ & $0.25 \pm 0.03^{\mathrm{a}}$ & $3.87 \pm 0.33^{\mathrm{a}}$ \\
$\mathbf{2 0}$ & $4.26 \pm 0.35$ & $9.20 \pm 0.12^{\mathrm{a}}$ & $0.25 \pm 0.01^{\mathrm{a}}$ & $3.85 \pm 0.06^{\mathrm{a}}$ \\
$\mathbf{2 5}$ & $4.26 \pm 0.35$ & $8.94 \pm 0.29^{\mathrm{a}}$ & $0.23 \pm 0.01^{\mathrm{a}}$ & $3.71 \pm 0.16^{\mathrm{a}}$ \\
$\mathbf{3 0}$ & $4.26 \pm 0.35$ & $9.12 \pm 0.49^{\mathrm{a}}$ & $0.24 \pm 0.02^{\mathrm{a}}$ & $3.80 \pm 0.27^{\mathrm{a}}$ \\
$\mathbf{3 5}$ & $4.26 \pm 0.35$ & $9.74 \pm 1.05^{\mathrm{a}}$ & $0.27 \pm 0.05^{\mathrm{a}}$ & $4.11 \pm 0.56^{\mathrm{a}}$ \\
\hline
\end{tabular}

Means with similar superscripts in the same column are not significantly different $(p>0.05)$

\subsubsection{Growth in weight}

After 20 days of rearing, the body weight of fish ranged from $0.243-0.28 \mathrm{~g}$ /fish, coinciding with DWG at 0.011-0.110 $\mathrm{g} /$ day, and SGRw was at $11.98-12.58 \%$ /day (Table 5), however, no statistical difference was recorded among treatments $(p>0.05)$. Previous studies highlighted that the better growth performance of fish was related to low metabolism due to reducing metabolic rates might result in energy savings that are directed toward growth (Swanson, 1998). Accordingly, at isotonic point, the energetic cost for osmoregulation is lower and the energy saved is sufficient enough to increase the growth of fish (Mookkan et al., 2014). However, salinity did not affect respiratory metabolism but did affect ammonia excretion rate in spotted scat juvenile (Xu et al., 2020). Moreover, low salinity could promote better digestion and absorption, which leads to better growth (Xu et al., 2020). In this study, no significant difference in fish growth could be explained by the short time of salinity exposure. 


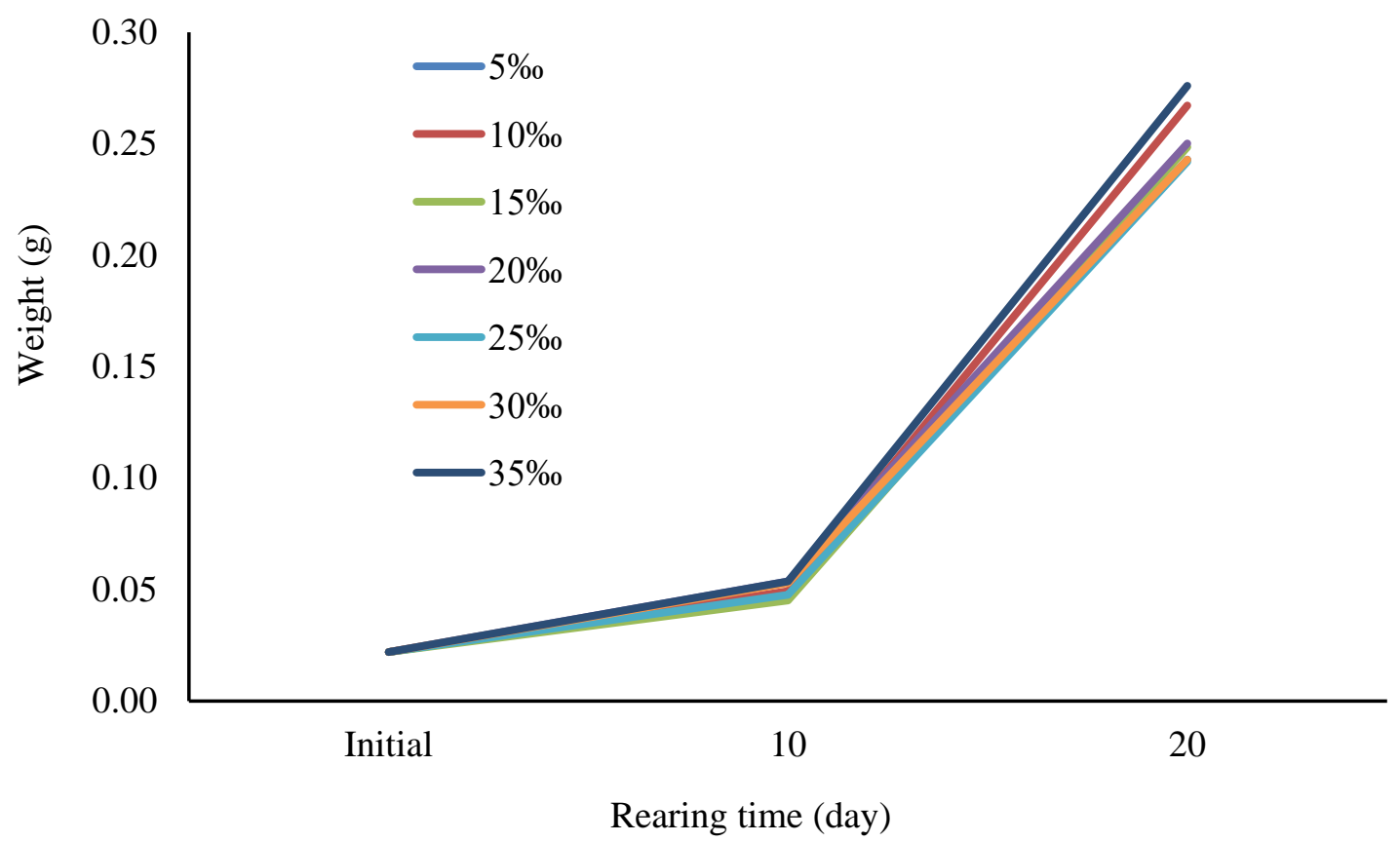

Figure 3: The body weight of fishes during the experimental time

According to Khanh et al. (2010), fishes reared at 5\% of salinity showed the highest body weight after 3 months (11.63 $\mathrm{g} /$ fish), whereby the DWG was at $0.14 \mathrm{~g} /$ day and SGRw was at
$1.48 \% /$ day. However, there was not significantly different $(p>$ $0.05)$.

Table 5: Growth in body weight of fishes after 20 days of rearing

\begin{tabular}{lllll}
\hline $\begin{array}{l}\text { Salinity level } \\
(\% \mathbf{\%})\end{array}$ & $\mathbf{W}_{\mathbf{i}}(\mathbf{g})$ & $\mathbf{W}_{\mathbf{f}}(\mathbf{g})$ & $\begin{array}{l}\text { DWG } \\
(\mathbf{g} / \mathbf{d a y})\end{array}$ & SGRw $^{(\% / \text { day })}$ \\
\hline $\mathbf{5}$ & $0.022 \pm 0.002$ & $0.243 \pm 0.025^{\mathrm{a}}$ & $0.110 \pm 0.001^{\mathrm{a}}$ & $11.99 \pm 0.49^{\mathrm{a}}$ \\
$\mathbf{1 0}$ & $0.022 \pm 0.002$ & $0.267 \pm 0.040^{\mathrm{a}}$ & $0.012 \pm 0.002^{\mathrm{a}}$ & $12.45 \pm 0.68^{\mathrm{a}}$ \\
$\mathbf{1 5}$ & $0.022 \pm 0.002$ & $0.250 \pm 0.035^{\mathrm{a}}$ & $0.011 \pm 0.002^{\mathrm{a}}$ & $12.09 \pm 0.71^{\mathrm{a}}$ \\
$\mathbf{2 0}$ & $0.022 \pm 0.002$ & $0.250 \pm 0.030^{\mathrm{a}}$ & $0.011 \pm 0.001^{\mathrm{a}}$ & $12.13 \pm 0.52^{\mathrm{a}}$ \\
$\mathbf{2 5}$ & $0.022 \pm 0.002$ & $0.243 \pm 0.021^{\mathrm{a}}$ & $0.011 \pm 0.001^{\mathrm{a}}$ & $11.98 \pm 0.38^{\mathrm{a}}$ \\
$\mathbf{3 0}$ & $0.022 \pm 0.002$ & $0.246 \pm 0.031^{\mathrm{a}}$ & $0.011 \pm 0.001^{\mathrm{a}}$ & $11.98 \pm 0.60^{\mathrm{a}}$ \\
$\mathbf{3 5}$ & $0.022 \pm 0.002$ & $0.280 \pm 0.052^{\mathrm{a}}$ & $0.013 \pm 0.003^{\mathrm{a}}$ & $12.58 \pm 1.03^{\mathrm{a}}$ \\
\hline
\end{tabular}

Means with similar superscripts in the same column are not significantly different ( $p>0.05)$

\subsection{Fish survival}

Fish survival after 20 days of rearing ranged from 56.7 $98.9 \%$ (Fig. 4). In which, the highest survival rate was recorded at $5 \%$ of salinity $(98.9 \%)$ and was significantly different compared to others $(p<0.05)$. Besides, the lowest survival rate was at $30 \% 0(56.7 \%)(p>0.05)$. Therefore, salinity remarkably affected on the survival of spotted scat at early juvenile stages. Khanh et al. (2010) reported that spotted scat juvenile reared at 0 , 5 and $10 \%$ of salinity showed high survival rate $(94.6-96.4 \%)$ and significantly higher than other treatments as $15(89.2 \%), 20$ $(84.7 \%), 25(73.0 \%)$, and 30\% $(70.3 \%)(p<0.05)$. 


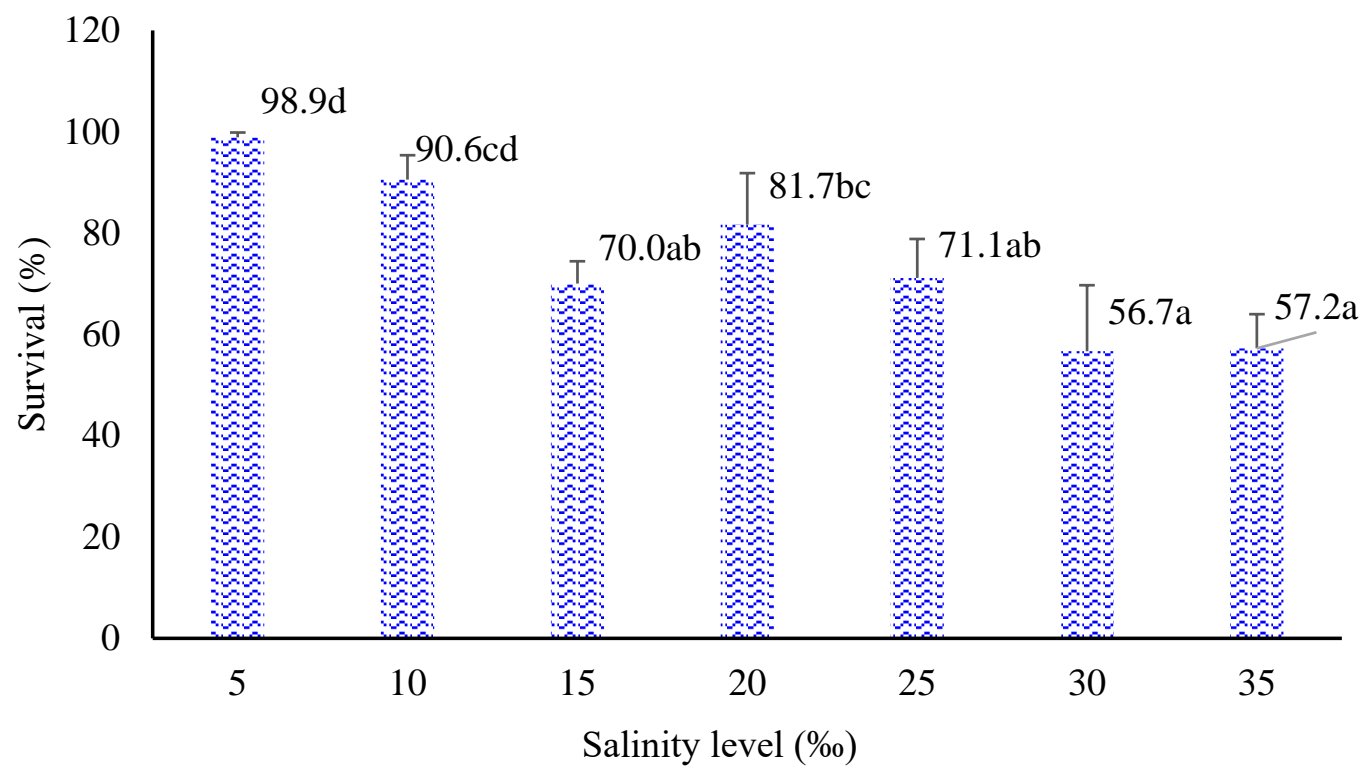

Figure 4: The survival rate of fishes after 20 days of rearing

Means with different superscripts are significantly different $(p<0.05)$

\section{CONCLUSION AND RECOMMENDATION}

\subsection{Conclusion}

The water quality including temperature, $\mathrm{pH}, \mathrm{DO}, \mathrm{TAN}$ and nitriteduring the experimental period were in a suitable range for normal growth of spotted scat juvenile. The results showed that spotted scat is a euryhaline fish with strong adaptability to salinity (5-35\%). However, at the early juvenile stage, spotted scat archived high survival at $5 \%$ and $10 \%$ of salinity, coinciding with $98.9 \%$ and $90.6 \%$.

\subsection{Recomendation}

The variation in salinity could influence number of physiological processes, therefore, it requires further studies on the influence of salinity on oxygen consumption, ammonia excretion, nutrient utilization of spotted scat

\section{ACKNOWLEDGEMENTS}

This study is funded by the Can Tho University Improvement Project VN14-P6, supported by Japanese ODA loan.

\section{REFERENCES}

[1] Boyd, C.E., 1998. Pond water aeration systems. Aquaculture Engineering. 18 (1): $19-40$

[2] Bœuf, G., Payan, P., 2001. How should salinity influence fish growth? Comp. Biochem. Physiol. - C Toxicol. Pharmacol. 130, 411-423. https://doi.org/10.1016/S1532-0456(01)00268-X

[3] Ern, R., Esbaugh, A.J., 2018. Effects of salinity and hypoxia-induced hyperventilation on oxygen consumption and cost of osmoregulation in the estuarine red drum (Sciaenops ocellatus). Comp. Biochem. Physiol. -Part A Mol. Integr. Physiol. 222, 52-59. https://doi.org/10.1016/j.cbpa.2018.04.013

[4] Ern, R., Huong, D.T.T., Cong, N. V., Bayley, M., Wang, T., 2014. Effect of salinity on oxygen consumption in fishes: A review. J. Fish Biol. 84, 12101220. https://doi.org/10.1111/jfb.12330
[5] Mookkan, M., Muniyandi, K., Rengasamy, T.A., Ramasubbu, S., Raman, V., Govindarajan, T., 2014. Influence of salinity on survival and growth of early juveniles of Spotted scat Scatophagus argus ( Linnaeus, 1766 ). Indian J. Innov. Dev. 3, 23-29.

[6] Quốc Viet, L., Khánh, L.V., Thông, L.V., Khoa, D., Tomonari, K., 2020. Effects of stocking densities on growth and survival rates of spotted scat (Scatophagus argus) fingerling reared in earthen ponds. J. Sci. Can Tho Univ. 56, 87-93. https://doi.org/10.22144/ctu.jsi.2020.042

[7] Khanh, L.V., Hai, T.N., Huong, D.T.T., Phuong, N.T., 2010b. Study on the reproductive biology of spotted scat (Scatophagus argus) in the mekong delta, Vietnam. J. Sci. Can Tho Univ. 14: 186-194. (In Vietnamese)

[8] Khanh, L.V., Hien, T.T.T., Hai, T.N., Phuong, N.T., 2010a. Effects of salinities on the growth and survival rates of Spotted scat fish (Scatophagus argus) fingerlings of 2 to 5 month-old stage. J. Sci. Can Tho Univ. 14: 177185. (In Vietnamese)

[9] Shao, Y.T., Hwang, L.Y., Lee, T.H., 2004. Histological observations of ovotestis in the spotted scat Scatophagus argus. Fish. Sci. 70, 716-718. https://doi.org/10.1111/j.1444-2906.2004.00863.x

[10] Swanson, C. 1998. Interactive effects of salinity on metabolic rate, activity, growth and osmoregulation in the euryhaline Milkfish (Chanos chanos). Journal of Experimental Biology 201:3355-3366

[11] Su, M., Duan, Z., Shi, H., Zhang, J., 2019. The effects of salinity on reproductive development and egg and larvae survival in the spotted scat Scatophagus argus under controlled conditions. Aquac. Res. 50, 1782-1794. https://doi.org/10.1111/are.14056

[12] Tacon, A. G. J., 1990. Standard methods for the nutrition and feeding of farmed fish and shrimp. Argent Laboratory. Press, Washington, DC, 1990, 454 pages.

[13] Tucker, J.W., 1998. The rearing environment. In: Harbor Branch Oceanographic Institution, Florida Institute for Technology, Kluwer Academic publisher. Marine fish culture, 49-146.

[14] Xu, J., Shui, C., Shi, Y., Yuan, X., Liu, Y., Xie, Y., 2020. Effect of salinity on survival, growth, body composition, oxygen consumption, and ammonia excretion of juvenile Spotted Scat. N. Am. J. Aquac. 82, 54-62. https://doi.org/10.1002/naaq.10117

\section{AUTHORS}

First Author - Le Quoc Viet, Associate Professor, College of Aquaculture and Fisheries, Can Tho University, Vietnam. Email: quocviet@ctu.edu.vn 
Second Author - Tran Ngoc Hai, Professor, College of Aquaculture and Fisheries, Can Tho University, Vietnam. Email: tnhai@ctu.edu.vn
Correspondence Author - Le Quoc Viet, College of Aquaculture and Fisheries, Can Tho University, Vietnam. Email: quocviet@ctu.edu.vn. Phone: (84)0913676863 